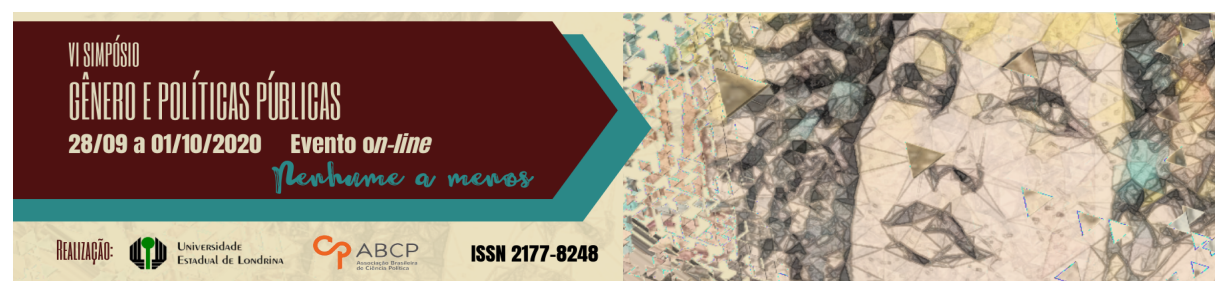

\title{
Entrega voluntária em adoção sob a perspectiva de cor/raça
}

\author{
Ana Lucia Oliveira Ramos ${ }^{1 ;}$ Renata Gonçalves ${ }^{2}$
}

\section{Resumo}

O presente artigo propõe uma discussão sobre as questões que, historicamente, levam as mulheres a realizarem a entrega voluntária do/a filho/a em adoção; o trabalho realizado no âmbito do judiciário e das políticas sociais, no sentido da oferta e garantia de direitos na história do Brasil; como as relações étnico-raciais interferem nesse fenômeno; como os/as profissionais apreendem essa questão no âmbito do trabalho realizado na Vara da Infância e Juventude no Foro Regional II Santo Amaro em São Paulo; bem como a análise dos dados referentes aos atendimentos realizados durante 2018, 2019 e durante a pandemia de COVID- 19 no ano de 2020.

Palavras-chave: criança; entrega voluntária; adoção.

\section{Voluntary delivery in adoption from a color / race perspective}

\begin{abstract}
This article proposes a discussion on the issues that, historically, lead women to voluntarily surrender their child in adoption; the work carried out within the scope of the judiciary and social policies, in the sense of offering and guaranteeing rights in the history of Brazil; how ethnic-racial relations interfere in this phenomenon; how professionals understand this issue within the scope of the work carried out at the Childhood and Youth Court at the Regional Forum II Santo Amaro in São Paulo; as well as the analysis of data referring to the consultations carried out during 2018, 2019 and during the COVID-19 pandemic in 2020.
\end{abstract}

Keywords: child; voluntary surrender; adoption.

\footnotetext{
${ }_{1}^{1}$ Mestranda no Programa de Pós-Graduação em Serviço Social e Políticas Sociais, UNIFESP, (nana_pucsp@yahoo.com.br).

2 Docente no Programa de Pós-Graduação em Serviço Social e Políticas Sociais, UNIFESP. Doutora em Ciências Sociais (rengon2011@gmail.com).
}

GT 01 - Amefricanizando o feminismo: mulheres negras saindo da invisibilidade. 


\section{Introdução}

O Tribunal de Justiça do Estado de São Paulo, através da Coordenadoria da Infância e Juventude, em parceria com a Secretaria Estadual da Saúde, Secretaria Estadual do Desenvolvimento Social e Grupo de Apoio à Adoção de São Paulo instituiu uma comissão para discutir o processo de entrega voluntária em adoção considerando o contexto em que genitoras deixam os recém-nascidos em vias públicas ou nos hospitais e maternidades. Uma das ações que integram as atividades da comissão foi a elaboração da cartilha: "Política de Atenção à Gestante: Apoio Profissional para uma Decisão Amadurecida Sobre Permanecer ou Não com a Criança", lançada no final de 2015.

Em análise da cartilha proposta e, em circulação, restou-me algumas inquietações, aqui brevemente apontadas em relação ao processo de entrega voluntária em adoção realizada por mulheres, em uma perspectiva racializada, na Vara da Infância e Juventude do Foro Regional II Santo Amaro (VIJ Santo Amaro). Mas antes, é de fundamental importância que ampliemos nosso olhar sobre a questão da maternidade e de como as políticas sociais, voltadas para as mulheres que não desejam assumir o exercício da maternidade, se estruturam no Brasil.

\section{O mito do amor materno}

Antes de falarmos da "Terra Tupiniquim" vale destacar que Elisabeth Badinter em 1981 já discutia a chamada vocação natural para a maternidade, afirmando que o amor materno não é um sentimento inerente à condição de ser mulher, mas se constituiu enquanto sentimento humano sujeito às mais diversas determinações e variações relacionadas ao momento histórico, social, político e econômico em que a sociedade está inserida.

A autora demonstra num percurso histórico como a 
maternidade era vivenciada na Europa, principalmente, durante os séculos XVII, XVIII, XIX e XX.

Ao se percorrer a história das atitudes maternas, nasce a convicção de que o instinto materno é um mito. Não encontramos nenhuma conduta universal e necessária à mãe. Ao contrário, constatamos a extrema variabilidade de seus sentimentos, segundo sua cultura, ambições e frustrações. Como, então, não chegar à conclusão, mesmo que ela pareça cruel, de que o amor materno é apenas um sentimento e, como tal, essencialmente contingente? Esse sentimento pode existir; ser e desaparecer. Mostrarse forte ou frágil. Preferir um filho ou entregar-se a todos. (...). Não, não há uma lei universal nessa matéria, que escapa ao determinismo natural. $\mathrm{O}$ amor materno não é inerente às mulheres. É "adicional" (BADINTER, 1985, Pg. 364).

Percebe-se nas constatações de Elisabeth Badinter a possibilidade de ausência do amor materno e, principalmente, como o contexto histórico, social, cultural, econômico e político interferem em como a sociedade trata e vivencia a maternidade. Vale destacar ainda que a cor/raça das mulheres também interfere de forma significativa na forma como elas vivenciam a maternidade e a possibilidade de escolha em exercê-la ou não. $\mathrm{O}$ que nos indica como a decisão por realizar a entrega "voluntária" do/a filho/a em adoção pode ser complexa e permeada de estereótipos, preconceitos e sofrimento.

\section{Uma história brasileira}

No Brasil, o fenômeno de mulheres que, de alguma forma, abrem mão do exercício da maternidade, se expressa desde o período imperial, quando crianças eram deixadas em locais públicos. Tais situações já demandavam preocupação do Estado em relação à infância "enjeitada" no Brasil e eram tratadas em ações assistencialistas desenvolvidas pelas Santas Casas de Misericórdia que atuavam na 
assistência à pobreza com uma perspectiva de caridade cristã e mantinham as Rodas dos Expostos como meio para receber as crianças "enjeitadas" sem que suas famílias fossem identificadas.

Somente os estabelecimentos da Santa Casa do Rio de Janeiro receberam mais de cinquenta mil crianças enjeitadas entre os séculos XVIII e XIX, o que assinala a dimensão do problema. Em alguns centros urbanos, no século XVIII, até $25 \%$ dos bebês eram abandonados e cerca de $70-80 \%$ faleciam antes de completar sete anos (TORRES, 2006, p. 105).

As Rodas dos Expostos eram formadas por uma caixa dupla em formato cilíndrico e foram adaptadas no muro das instituições caridosas. Com a janela aberta para o lado externo, um espaço dentro da caixa recebia a criança e após, rodava-se o cilindro para o interior dos muros, desaparecendo assim a criança aos olhos externos; dentro da edificação a criança era recolhida (...) (SANTA CASA DE MISERICÓRDIA, 2018). Lá eram deixadas crianças indesejadas por suas famílias, mas principalmente, os filhos de mulheres escravizadas. Ora por suas mães serem escolhidas como amas-de-leite para os filhos dos "senhores", ora pelos proprietários que não desejavam se responsabilizar pelos encargos da criação da prole de seus escravos ou como forma das mães livrarem seus filhos da escravidão (CIVILETTI, 1991, p. 34).

Em sua pesquisa, Maria Vittoria Pardal Civiletti encontra informações sobre a quantidade de crianças recebidas na Roda dos Expostos do Rio de Janeiro, entre os anos de 1738 e 1899. A autora conclui que a diminuição do número de crianças atendidas se dá,

provavelmente, em decorrência da Lei do Ventre Livre (1871) e, posteriormente, com a abolição (CIVILETTI, 1991, p. 35).

A responsabilidade pelo trato da entrega de crianças "indesejadas" e mesmo a prestação de serviços no âmbito da saúde não possuíam qualquer regulamentação ou sistematização e estavam sujeitas aos diversos acordos entre a esfera pública e a privada de 
forma em que a criança era desprovida de humanidade e direitos.

A partir da década de 30, como descreve Boschetti (2006, p. 10) que o Estado passa a intervir de forma sistemática na regulação das relações de trabalho e na área social - esta última, também se configurando como seu objeto de atuação em um contexto de intensa modernização do setor urbano industrial. Essas modificações no modo de produção - que deixou de ser baseado na escravidão e passou a ser constituído por relações de trabalho com o homem livre, branco e imigrante - alteram também a esfera da reprodução das relações sociais. Neste contexto, a imagem da mulher branca é colocada como ser supremo e responsável pelo bem-estar da família e deve permanecer em casa, cuidando do lar, como forma de garantir a reprodução da força de trabalho e de sujeitos "de boa índole".

É esse um dos discursos que contribui para atribuir à mulher a educação e o cuidado com a prole, por meio de um processo de romantização e idealização da figura materna. No século XX a figura da ama-de-leite já não existe mais e os intelectuais adeptos da eugenia visavam reformular a conduta das mulheres das classes abastadas em relação aos filhos (CIVILETTI, 1995, p. 35), ao mesmo tempo em que as classes dominantes se preocupava em disciplinar os trabalhadores em uma perspectiva higienista. $O$ objetivo era preparar o país para o desenvolvimento. A pobreza foi associada à promiscuidade, ao vício, à ignorância e, portanto, à incapacidade para cuidar das crianças, futuro da nação. O governo brasileiro então, estabelece legislações com o intuito de "salvar a família, para proteger a criança" (RIZZINI \& PILOTTI, 2011, p. 270).

Em meio ao avanço da exploração dos/as trabalhadores/as, do processo de marginalização dos/as negros/as após a abolição e o aumento da pobreza, cresce o contingente de crianças "abandonadas" circulando no espaço público e buscando estratégias para sua sobrevivência, o que passou a preocupar o poder público. Ao mesmo tempo, as teorias de supremacia branca ganhavam corpo, assim como 
o projeto de embranquecimento da população brasileira.

Em meio ao emergente conflito de classes e processos de reivindicações que marcam o início do século $\mathrm{XX}$, foi criado o Juizado de Menores e, pouco tempo depois, o Código de Menores, voltado para o atendimento de crianças em "situação irregular" ou de "abandono".

Pereira (1992, p. 18) demonstra que

Em 1940, o governo criou uma política de proteção materno-infantil, tendo como meta a preparação do futuro cidadão, de acordo com a concepção de cidadania da época, isto é, a formação do trabalhador como "capital humano" do país, através do preparo profissional, e o respeito à hierarquia através da educação da criança (apud RIZZINI; PILOTTI, 2011, p. 262).

O Decreto-lei n 2.024 de 17/02/1940 era responsável por “fixar as bases da organização da proteção à maternidade, à infância e à adolescência em todo o País", em pleno Estado Novo. Antes disso, porém, o Código de Menores de 1926 já destinava atenção aos "infantes expostos"3.

Essas crianças eram encaminhadas para as instituições assistenciais e as mães que realizavam a entrega voluntária não eram obrigadas a se identificarem ou a assinarem qualquer documentação no processo de entrega. Porém, aqui, já havia a possibilidade de serem atendidas por funcionários da instituição e fornecerem informações sobre a criança e, principalmente, se inicia a obrigatoriedade do registro de seu nascimento.

Os "menores", assim como a presença de uma vasta população negra (a maior fora de África) então, foram considerados como um dos fatores para o subdesenvolvimento (LAGE; ROSA, 2011, s/p) e, portanto, passíveis não apenas de correção, mas principalmente de

3 Eram considerados "infantes expostos" todas as crianças de até sete anos encontrados em estado de "abandono". 
controle da delinquência e da criminalidade, em um processo de verdadeira criminalização e culpabilização da pobreza.

Nesse cenário a FEBEM assume importante papel ao receber os filhos da população mais empobrecida e relegada à marginalização, em sua maioria negros, e ao se constituir enquanto o internato dos pobres (FONSECA, 2002, p. 101).

Em meados da década de 1970 o mundo observou a chamada "crise do modo de produção capitalista". A intervenção crescente do Estado na economia num cenário de profunda crise do processo de acumulação dá origem à reação neoliberal, o que por si só propõe mudanças no papel e na atuação do Estado a partir dos preceitos de "flexibilização", "desregulamentação" e "privatização", contribuindo para que o capital financeiro pudesse ultrapassar as fronteiras dos Estados (NETTO, 2012).

No Brasil, as determinações desse processo econômico já se manifestam a partir da abertura democrática pós ditatura militar. A Constituinte nasce enquanto fruto de disputa entre os interesses das classes dominantes e da classe trabalhadora, num contexto cheio de contradições e projetos distintos de Brasil, no qual se deu as condições para as mudanças jurídico-legais sobre a infância no país.

O Estatuto da Criança e do Adolescente (ECA) inaugura uma nova percepção de infância e, consequentemente do arcabouço jurídico-legal. A legislação vigente deixou de atuar na perspectiva do controle, para atuar na perspectiva de proteção.

\section{Entrega voluntária e políticas sociais}

No curso da história, observa-se que as mudanças jurídicolegais se dão em resposta às modificações do pensamento e das vivências sociais. Com o avanço dos pressupostos liberais, não apenas na economia ou política, mas também no âmbito jurídico e mesmo das 
relações sociais, observa-se o avanço situacionista do Estado ao considerar a maternidade como uma escolha e, assim, fornecer respaldo legal para a entrega voluntária do filho em adoção.

O ECA, embora inovador, e regulamentando ações de proteção à maternidade, inicialmente não se referia especificamente à entrega voluntária de crianças em adoção. Ao mesmo tempo, em seu Art. 238 o qualificava enquanto crime "prometer ou efetivar a entrega de filho ou pupilo a terceiro, mediante paga ou recompensa" sob pena de reclusão.

Em 1991 a legislação sofre sua primeira modificação. A Lei $n^{\circ}$ 8.185, de 14 de maio de 1991, na Seção V, Art. 29, § III e § IV, estabelecia que, à então Vara de Órfãos e Sucessões caberia "praticar os atos relativos à tutela de órfãos" e "praticar os atos de jurisdição voluntária necessários à proteção de órfãos e à guarda e administração de seus bens". A legislação se limitava à regulamentação em relação às crianças órfãs, sem referência explícita à entrega voluntária em adoção. O que só se observa, na legislação brasileira, a partir da Lei $n^{0} 12.010$, de 03 de agosto de 2009.

Mas antes de nos referirmos à lei propriamente dita, é importante salientar que aqui, não falamos de abandono ou doação, mas partimos do conceito de entrega voluntária em adoção como o ato que consiste na desistência da mãe de criar o filho que espera ou que já concebeu e entregá-lo para que outros o façam em seu lugar (...), livre de juízos de valor moral sobre a mulher que entrega o/a filho/a em adoção, a partir de um direito garantido por lei (MOTTA, 2015, p. 59$60)$.

A partir da inclusão do conceito de entrega voluntária no arcabouço jurídico, é possível que uma gestante ou mãe entregue seu filho/a em adoção através de processo promovido na VIJ. Nesse sentido, ao proceder com os trâmites previstos em lei, a mulher tem sua conduta assegurada e, por isso, não comete crime, uma vez que a entrega visa garantir e preservar os direitos e interesses da criança no 
contexto de um país em que a interrupção voluntária da gestação é criminalizada.

Após alterações, o Art. 8 do ECA, em seus $\S 4^{\circ}$ e $\S 5^{\circ}$, define, respectivamente, que "incumbe ao poder público proporcionar assistência psicológica à gestante e à mãe, no período pré e pós-natal, inclusive como forma de prevenir ou minorar as consequências do estado puerperal" e "a assistência referida no $\S 4^{\circ}$ deste artigo deverá ser também prestada a gestantes ou mães que manifestem interesse em entregar seus filhos para adoção". Já o Art. 13, em seu Parágrafo Único dispõe que "as gestantes ou mães que manifestem interesse em entregar seus filhos para adoção serão obrigatoriamente encaminhadas à Justiça da Infância e da Juventude".

A Lei $n^{0}$ 12.010, que traz importantes alterações no ECA, principalmente em relação ao processo de adoção no Brasil, ainda fala sobre o atendimento das mulheres no âmbito do judiciário, dos serviços de saúde e dos demais programas de atendimento vinculados às políticas sociais, quando manifestarem o desejo pela entrega voluntária do/a filho/a em adoção. E, após quase dois séculos da implantação da roda dos expostos, a entrega voluntária passa a figurar em meio à normatização vigente no país, agora, em uma perspectiva de direito e vinculada às instituições oficiais do Estado como forma de proteger a criança - evitando sua exposição ao "abandono" - e à genitora - garantindo seu direito de "abrir mão do/a filho/a" com todo o amparo das políticas sociais.

A mulher que deseja realizar a entrega voluntária do filho em adoção poderá se manifestar ainda durante a gestação e, segundo a política estabelecida, deverá receber apoio no processo de reflexão para "uma decisão amadurecida sobre permanecer ou não com a criança" (TJSP, 2015).

Em 2017 assistimos à nova modificação do ECA com a, vulgarmente chamada "Nova Lei de Adoção". A Lei no 13.509 de 22 de novembro de 2017 define no Art. 19-A que a gestante ou mãe que 
manifeste interesse em entregar o/a filho/a em adoção deverá ser encaminhada para atendimento na Justiça da Infância e Juventude. A legislação ainda traz inovações ao se referir ao atendimento da mulher pelos profissionais da equipe interprofissional da Justiça da Infância e Juventude, conhecida como Setor Técnico (ST), formada por assistentes sociais e psicólogos. A lei ainda versa sobre o direito da mãe ao sigilo

em relação ao nascimento do bebê e traz outras determinações acerca da possibilidade de suspensão do poder familiar e prazos para a busca de família extensa, quando o caso.

A política prevê a intervenção dos serviços de saúde, assistência social e do judiciário de forma integrada para garantir o atendimento dessas mulheres. Mas será isso um avanço na garantia de direitos? Considerando o contexto de agudização das desigualdades, avanço do neoliberalismo e do processo de enxugamento das políticas sociais, será que podemos enfim dizer que a entrega do/a filho/a em adoção é de fato uma decisão voluntária?

Tomar como certa a participação no processo de decisão torna-se entretanto impossível quando sabemos que muitas mães sofrem pressões de diferentes níveis, seja no social, no institucional ou no familiar. As pressões costumam atuar em duas direções opostas, o que as impede de trabalhar seus sentimentos ambivalentes, intensificando-os e afastando-as da oportunidade de uma elaboração de sua decisão (MOTTA, 2015, p. 57).

A Sintese de Indicadores Sociais do IBGE de 2016, apontou que pretos e pardos somavam $54 \%$ da população brasileira, mas figuravam entre os 75,5\% mais pobres no Brasil (IBGE, 2016, p. 96). Em seu livro Adoção de Crianças Negras: inclusão ou exclusão? a autora Ana Maria da Silveira defende que os sujeitos discriminados por particularidades raciais e que integram o rol dos excluídos nos procedimentos de adoção são provenientes das camadas mais pobres da sociedade. $\mathrm{O}$ que nos leva a considerar que a população negra é a mais afetada pela ausência ou ineficiência das políticas públicas e, consequentemente, 
são expropriadas de seus filhos em processos de destituição do poder familiar.

As famílias negras brasileiras lideram o ranking, quando o assunto é a incapacidade de cuidar de seus membros, de maneira adequada, com provimento de moradia, alimentação, vestimenta, educação, cultura, lazer, saúde, segurança, entre outros direitos fundamentais. Em outros termos, os dados revelam a persistência da pobreza geracional, ocasionada pelo racismo, que impacta no modo de vida destas pessoas, nos diversos ciclos da vida, com ênfase maior sobre suas crianças e adolescentes, dependentes da capacidade protetiva dos adultos para se desenvolverem de maneira saudável (EURICO, 2018, p. 89).

Marcia Eurico, em sua tese de doutorado, faz uma importante discussão sobre como o racismo institucional se expressa tanto no cotidiano das famílias negras empobrecidas, quanto na rotina dos serviços de acolhimento onde as crianças dessas famílias permanecem por longo período.

A autora nos demonstra, de forma emocionada e emocionante como os serviços de acolhimento institucional incorporam práticas irrefletidas e carregadas de ideologia reproduzindo o racismo institucional. Ela afirma que o público alvo desses serviços possui história, classe social e raça/cor (EURICO, 2018, p. 189).

Mas se temos essa constatação no que se refere às medidas de acolhimento institucional, como se dá a proporção de mulheres negras que buscam o atendimento referente à entrega voluntária em adoção?

\section{Entrega voluntária em adoção e a vara da infância e juventude}

E é neste cenário em que a VIJ Santo Amaro realiza atendimentos às gestantes ou puérperas - que procuram o serviço espontaneamente ou são encaminhadas por instituições hospitalares e 
serviços da rede socioassistencial -, que manifestam o desejo pela entrega do/a filho/a em adoção.

As gestantes são atendidas no plantão do ST por uma dupla de profissionais composta por um assistente social e um psicólogo. A equipe realiza a escuta e orientações/reflexões com a mulher considerando a manifestação do desejo pela entrega voluntária em adoção e a motivação para tal escolha. Se o desejo pela entrega voluntária se confirma de forma aparentemente segura, o processo jurídico é aberto e a mulher orientada quanto a necessidade de retornar ao ST após o nascimento da criança para realizar a entrega em audiência ou, caso ocorra a desistência, informar sobre o desejo de permanecer com a criança para que o processo seja arquivado.

O mesmo atendimento é ofertado às puérperas. Após o parto, ao informar para a equipe hospitalar o desejo pela entrega voluntária do/a filho/a em adoção, quando da alta hospitalar, a mulher é encaminhada para atendimento na VIJ, enquanto o/a recém-nascido/a permanece no hospital. Imediatamente após o atendimento no ST a mulher é encaminhada para audiência ${ }^{4}$ para realizar oficialmente a entrega voluntária do/a filho/a em adoção perante o juízo. Nesses casos, após a concretização da entrega na audiência, o ST realiza imediatamente a busca de pretendentes habilitados/as para adoção que tenham o perfil compatível com a criança recém-nascida. Assim, o/a bebê é inserido/a em família substituta.

Se propõe às mulheres, quando ainda gestantes ou após o parto o atendimento nos serviços de saúde e assistência social, quando se identifica a necessidade. Durante a gestação, o apoio e assistência adequados podem contribuir para um processo de reflexão com maior qualidade e segurança e, consequentemente na busca por alternativas que podem resultar na mudança desse "desejo".

4 Participam da audiência o/a magistrado/a, o/a promotor/a representante do Ministério Público, a puérpera e, lhe representando, o/a defensor público/a. 
A legislação garante à mulher o direito de retratação ${ }^{5}$ de sua decisão, mas não especifica o prazo para que isso ocorra. Ao mesmo tempo, prevê que as crianças não procuradas por sua família em até trinta dias sejam encaminhadas para adoção.

Segundo dados de abril de 2018 do Cadastro Único, do total de quase 14 milhões de famílias beneficiárias do Programa Bolsa Família, mais de $90 \%$ eram lideradas por mulheres e, desse total, $75 \%$ por mulheres negras (MDS, 2018, p.8).

Quando falamos de vivência de violência e/ou negligência, 70,8\% são pessoas pretas e pardas e $28 \%$ brancas. Em situação de abuso e/ou exploração sexual, $68,6 \%$ dos participantes do serviço são pretos e pardos e $29,8 \%$ são brancos. Já quanto às crianças e adolescentes em situação de rua, 77,9\% são pretos e pardos e 20,7\% são brancos (MDS, 2018, p. 9).

Ou seja, as mulheres negras são o grupo majoritário no atendimento da Política de Assistência Social, além de figurarem na base da pirâmide social por receberem menores salários do que as mulheres brancas e homens negros. Essas são algumas das expressões do racismo estrutural e demonstram como a população negra é a maior dependente das políticas sociais. O que nos leva a pensar que essa, possivelmente, é a população mais atendida na esfera do judiciário, onde o racismo institucional se expressa tanto em sua configuração profissional, quanto em suas práticas.

Ao analisar o trabalho desenvolvido pelo ST na VIJ Santo Amaro, apesar dos atendimentos sobre a entrega voluntária em adoção ocorrerem com regularmente, observou-se uma deficiência na coleta e sistematização dos dados, o que trouxe importante prejuízo ao caminho reflexivo proposto neste artigo e para a própria compreensão

5 Conforme definição do Dicionário Jurídico DireitoNet "trata-se de termo que significa voltar atrás no que disse, assumir o erro ao fazer uma imputação a alguém". Segundo o Dicionário Michaellis "ato ou efeito de retratar-se, de desdizer-se. Confissão de erro. Desmentido". 
de como esse fenômeno se expressa no cotidiano. Por outro lado, a insuficiência de informações nos chama a atenção para a importância da sistematização do trabalho profissional como ferramenta para identificação, análise e proposição diante das diversas expressões da questão social, como defende Fávero (2005):

Ao estudo do passado, enquanto possibilitador de compreensão das práticas do presente e orientador de um futuro que busque concretizar práticas compromissadas com a competência técnica, política e ética e com a consequente garantia de direitos de cidadania, deve se alinhar novos estudos sobre o presente, com indicações de propostas concretas para tal exercício - já que esse é um campo em que a profissão é necessária - para, entre outas, possibilitar explicações mais amplas da realidade e contribuir para a garantia de direitos. Campo no qual tem possibilidades de se expandir, pelas exigências reais e também legais (FÁVERO, 2005, p. 126-7).

Entre o período de agosto de 2018 e abril de 2019 foram registrados os atendimentos de 20 mulheres que manifestaram o interesse pela entrega voluntária em adoção. Após as diferentes intervenções e atendimentos realizados pelos assistentes sociais e psicólogos do ST, todas confirmaram a entrega voluntária em audiência. Porém, não há registro de quantas dessas mulheres foram encaminhadas para atendimento das diferentes políticas sociais, nem referência quanto à auto ou heteroidentificação de cor/raça. Em um esforço para obter maiores informações junto à equipe técnica, identificou-se que as 20 crianças foram encaminhadas para família substituta.

Se a localização dos dados referentes aos atendimentos realizados já era difícil, com a pandemia do COVID-19 tornou-se inviável. A equipe do ST da VIJ Santo Amaro passou a atuar profissionalmente em sistema de home office, assim os relatórios dos atendimentos deixaram de ser socializados em equipe, uma vez que 
cada profissional armazenou os dados em seus recursos pessoais.

A partir das análises dos relatórios produzidos em decorrência dos atendimentos realizados pelo ST entre janeiro e março de 2020, observamos que 7 mulheres manifestaram o interesse pela entrega voluntária do/a filho/a em adoção. Em apenas 2 relatórios havia a referência em relação à autodeclaração de cor/raça dessas mulheres (1 branca e 1 parda). Nas demais cinco situações, em conversa com as técnicas responsáveis pelo atendimento foi possível identificar a cor/raça das mulheres segundo a heteroidentificação das assistentes sociais (5 pardas). Nenhuma das mulheres foi identificada como preta.

Dentre as principais motivações para a entrega voluntária apareceram: dificuldades financeiras (3 mulheres); conflitos familiares (3 mulheres), ausência de afeto pela criança ou de desejo em exercer a maternidade (3 mulheres); relação abusiva ou violência sexual (2 mulheres), uso de drogas (1 mulher). Em algumas situações houve a manifestação de duas ou mais motivações associadas.

Portanto, apesar da perspectiva de direito que se atribui à entrega voluntária em adoção, na realidade, o que se configura é a predominância de dificuldades financeiras e conflitos familiares como motivações para essa "escolha". Observamos ainda que apenas 1 mulher branca buscou o referido atendimento, o que corrobora com a hipótese de que as mulheres negras também são maioria na busca pela entrega do/a filho/a em adoção.

Não há maiores informações que permitam a ampliação da análise quantitativa e qualitativa em relação às mulheres que buscaram atendimento para a entrega voluntária em adoção. Da mesma forma, evidencia-se a ausência de informações acerca da auto- identificação de cor/raça dessas mulheres e de um olhar voltado para os determinantes étnico-

raciais que atravessam essas vivências, o que se configura como um importante entrave para a produção de avanços e propostas 
efetivas para o atendimento dessas mulheres e crianças em uma perspectiva emancipadora e pela eliminação de todas as formas de preconceito, incentivando o respeito à diversidade, à participação de grupos socialmente discriminados e à discussão das diferenças (CFESS, 2012, p. 23).

A entrega voluntária em adoção - apesar de se configurar como importante direito para mulheres em um país cujo marco legal criminaliza a interrupção gestacional pelo livre desejo da mulher - se apresenta enquanto alternativa para as mulheres que, por questões econômicas e conflitos familiares abrem mão, ou porquê não dizer, são obrigadas a abrirem mão, do exercício da maternidade.

Embora seja possível notar um esforço em desmistificar o processo de entrega voluntária como "abandono" e o elevar ao status de direito, no âmbito do judiciário, é que a operacionalização da política se faz de modo pouco reflexivo frente ao campo reduzido das políticas sociais. Ou seja, a intervenção do Estado, historicamente, promove a "expropriação consentida" das crianças de mulheres negras e pobres - mesmo com a ausência de acesso às políticas sociais enquanto fator determinante ou influenciador para a entrega de seus filhos/as em adoção.

As consequências do ajuste neoliberal para a política social, por sua vez, são enormes, não só porque o aumento do desemprego leva ao empobrecimento e ao aumento generalizado da demanda por serviços sociais públicos, mas porque se corta gastos, flexibiliza-se direitos e se propõe, implícita ou explicitamente, a privatização dos serviços (...) (TELLES, 1998, apud BEHRING, 2008, p. 161-2).

Nesse sentido, apesar do aparente avanço em relação às políticas voltadas para alguns segmentos da população (mulheres, negros, LGBTQ+, etc.), a proposta de atendimento para as mulheres é ainda questionável, principalmente no que se refere à política de saúde 
e de assistência social6. Mas, inegavelmente, as políticas sociais ainda demonstram de forma mais evidente as desigualdades raciais que assolam a população, enquanto o judiciário não apresenta espaço efetivo para o debate das questões raciais e como elas atravessam os/as sujeitos/as. O racismo institucional se reproduz à luz do mito da democracia racial e parece não existir, assim como as mulheres pretas e pardas, e as desigualdades raciais a que estão submetidas.

E é nesse contexto neoliberal, de mercantilização e financeirização dos direitos sociais e da vida, de aprofundamento da exploração e expropriação das classes subalternas por parte do capital e de acirramento das desigualdades raciais que as mulheres devem "refletir para uma decisão amadurecida" em relação à entrega do filho em adoção. Será que ainda assim, podemos afirmar que essa entrega realmente é voluntária?

\section{Considerações Finais}

Apesar da disseminação do mito do amor materno e da idealização da mãe, a entrega voluntária de crianças em adoção é um fator presente na sociabilidade humana. No Brasil, a prática chegou a mobilizar o que consideramos como uma das primeiras políticas sociais voltadas para a infância no país, a implantação das Rodas dos Expostos.

Mas, se às mulheres das classes mais abastadas havia a possibilidade de escolha pela entrega voluntária do/a filho/a em adoção, às mulheres negras escravizadas essa prática não se colocava efetivamente de forma "voluntária". Assim, além de serem entregues nas Rodas, os filhos e filhas de mulheres escravizadas podiam ser

\footnotetext{
${ }^{6}$ A saúde, atualmente fragmentada e terceirizada não alcança seu caráter universal, o que contribui para a ausência de atendimento integral de segmentos cada vez mais pauperizados. $\mathrm{O}$ que também se percebe em relação à assistência social, restrita aos programas de transferência de renda, na lógica de mercantilização e financeirização dos serviços.
} 
vendidos/as e enviados/as para longe como bezerros separados das vacas (DAVIS, 2016, p. 19-21), impossibilitando a convivência e a criação de vínculos afetivos entre mãe e filho/a.

Já no início do século XX, a entrega "voluntária" das crianças ocorria na FEBEM, local onde os/as filhos/as da população empobrecida eram institucionalizados/as e, por vezes, encaminhados/as para lares substitutos (FONSECA, 2002, p. 110).

Após a abertura democrática no Brasil, com o avanço do neoliberalismo e o processo de mercantilização das políticas sociais, ao mesmo tempo em que a legislação avança no intuito de promover às mulheres o direito de abrir mão do exercício da maternidade de forma legal e segura, o que se vê é um sistema de atendimento que contribui para a expropriação das crianças das classes subalternas, atualmente entregues para a satisfação de outros grupos que atuam fortemente pressionando o Estado por medidas que facilitem o processo adotivo.

Vimos ainda que, no ano de 2020, entre os meses de janeiro e março, das 7 mulheres que buscaram o poder judiciário manifestando o desejo pela entrega voluntária em adoção, 6 integram a população negra brasileira. Notou-se ainda que a prática de aferição quanto a auto- identificação em relação à cor/raça não é recorrente na VIJ Santo Amaro, o que dificulta a compreensão de como as desigualdades raciais incidem sobre a população atendida e, consequentemente, contribuiu para sua invisibilização e para a perpetuação do racismo institucional.

Reforçamos que em um país que se estruturou a partir da subalternização, marginalização e genocídio do povo negro, não há como garantir justiça sem considerar as relações étnico-raciais. E se no período colonial as mulheres negras eram expropriadas de seus filhos, na contemporaneidade pouca diferença se observa frente à entrega "voluntária" em adoção.

Ainda há muito o que se compreender sobre as determinações 
que incidem sobre a entrega voluntária em adoção. Se essa busca está atrelada à ampliação das informações quanto ao direito das mulheres em abrir mão do exercício da maternidade. Se, por outro lado, essa demanda se coloca em um contexto de recrudescimento da pobreza em conjunto com a precarização e dificuldade de acesso às políticas sociais por parte das populações mais empobrecidas. E, principalmente, como as questões de classe social, gênero e raça/etnia atravessam as narrativas e o cotidiano das mulheres que buscam o judiciário com essa demanda.

Uma vez superada a discussão sobre a existência do racismo estrutural na sociabilidade brasileira, torna-se imperioso que os profissionais que atuam no atendimento direto à população, em todos os serviços e esferas de atendimento, principalmente no âmbito das políticas sociais e do Poder Judiciário se apropriem dessa questão como forma de contribuírem para a superação do racismo institucional e para a construção de práticas anti- racistas.

Assim, concluímos nossas reflexões propondo um aprofundamento sobre a compreensão das questões de classe social, gênero e raça/etnia que levam mulheres a buscarem o atendimento nas VIJ's manifestando o interesse pela entrega voluntária do/a filho/a em adoção, bem como sobre as respostas das políticas sociais e dojudiciário.

Só assim, após analisar a multiplicidade de fenômenos que atravessam essa manifestação de desejo, dentre elas as questões étnicoraciais, os profissionais poderão desenvolver práticas e intervenções que enxerguem as mulheres em suas múltiplas dimensões e respeitem as suas escolhas - convergindo na busca pela ampliação do acesso aos seus direitos, bem como na proteção das crianças.

\section{Referências}

BADINTER, Elisabeth. Um amor conquistado: o mito do amor materno. 
Rio de Janeiro: Nova Fronteira, 1985.

BEHRING, Elaine Rossetti. Brasil em contra-reforma: desestruturação do Estado e perda dos direitos. São Paulo: Cortez, 2008.

BOSCHETTI, Ivanete. Seguridade Social e Trabalho: paradoxos na construção das políticas de previdência e assistência social no Brasil. Brasília: Editora UNB, 2006.

BRASIL. Decreto $n^{\circ} 5.083$, de $1^{\circ}$ de dezembro de 1926.

BRASIL. Decreto-Lei $n^{\circ}$ 2.024, de 17 de fevereiro de 1940.

BRASIL. Constituição da República Federativa do Brasil, 1988.

BRASIL. Lei $n^{\circ}$ 8.069, de 13 de julho de 1990.

BRASIL. Lei $n^{\circ}$ 8.185, de 14 de maio de 1991.

BRASIL. Lei $n^{\circ}$ 12.010, de 3 de agosto de 2009.

BRASIL. Lei $n^{\circ}$ 13.509, de 22 de novembro de 2017.

CFESS. Código de ética do/a assistente social. Brasília, 2012. Disponível em: http://www.cfess.org.br/arquivos/CEP_CFESS-SITE.pdf. Acesso em: 05 set. 2020.

CIVILETTI, Maria Vittoria Pardal. O cuidado às crianças pequenas no Brasil escravista. Cadernos de Pesquisa, São Paulo, n. 76, p. 31-40, fev. 1991.

DAVIS, Ângela. Mulheres, raça e classe. São Paulo: Boitempo, 2016.

EURICO, Marcia Campos. Preta, preta, pretinha: o racismo institucional no cotidiano de crianças e adolescentes negras(os) acolhidas(os). São Paulo, 2018. Tese (Doutorado em Serviço Social) - Pontifícia Universidade Católica, São Paulo, 2018.

FÁVERO, Eunice Teresinha. Serviço Social, práticas judiciárias, poder: implantação e implementação do serviço social no juizado da infância e da juventude de São Paulo. São Paulo: Editora Veras, 2005.

FONSECA, Claudia. Caminhos da adoção. São Paulo: Cortez, 2002.

IBGE. Síntese de indicadores sociais: uma análise sobre as condições de vida da população brasileira. 2016. Disponível em: https:// biblioteca.ibge.gov.br/visualizacao/livros/liv98965.pdf. 
Acesso em: 10 mar. 2020.

LAGE, Michelle Torres; ROSA, Marco André Cernev. Evolução da infância no Brasil: do anonimato ao consumismo. Revista Eletrônica de Educação, ano IV, n. 8, s/p, 2011.

MANDEL, Ernest. O Capitalismo Tardio. São Paulo: Abril Cultural, 1982.

MDS. SUAS sem racismo: promoção da igualdade racial no Sistema Único de Assistência Social. Brasília, 2018. Disponível em: http://www.mds.gov.br/webarquivos/publicacao/assistencia_soci al/cartilhas/Cartilha_SUAS_Sem_Racismo_.pdf. Acesso em: 05 set. 2020.

MOTTA, Maria Antonieta Pisano. Mães abandonadas: a entrega de um filho em adoção. São Paulo: Cortez, 2015.

NETTO, José Paulo. Crise do capital e consequências societárias. Serv. Soc. Soc., n. 111, p. 413-429, 2012.

RIZZINI, Irene; PILOTTI, Francisco (Org.). A Arte de governar crianças: a história das políticas sociais, da legislação e da assistência à infância no Brasil. São Paulo: Cortez, 2011.

Santa Casa de Misericórdia de São Paulo. Disponível em: https://www.santacasasp.org.br/portal/site/quemsomos/museu/ curiosidades. Acesso em: 01 maio 2019.

SILVEIRA, Ana Maria da. Adoção de crianças negras: inclusão ou exclusão?. São Paulo: Veras, 2005.

TJSP. Política de Atenção à Gestante: Apoio Profissional para uma Decisão Amadurecida Sobre Permanecer ou Não com a Criança. São Paulo, 2015.

TORRES, Luiz Henrique. A casa da roda dos expostos na cidade do Rio Grande. BIBLOS, [S.1.], v. 20, p. 103-116, abr. 2008. 